\section{The Authors respond:}

We thank Dr G Sebastiani and colleagues from Montreal (Quebec) and Dr Borgia from Brampton (Ontario) for their interest in our article. Their eloquent comments only confirm that from all possible perspectives, clinical efficacy, patient safety and cost effectiveness, transient elastography (Fibroscan, Echosens, France) should be the standard of care for the staging of fibrosis in chronic liver disease today and must be the standard of care in the very near future. To subject patients to a potentially hazardous, invasive procedure when a safer alternative is available should be malpractice if it were not for the fact that Fibroscan outside of Quebec, is unfunded and largely unavailable. Similarly, forcing patients to choose between undergoing a hazardous, invasive procedure simply to meet a government requirement for coverage of an expensive but curative antiviral treatment, or suffering financial hardship by paying for the antiviral therapy out of pocket or going without treatment, may be viewed by many as oppressive and un-Canadian. Hopefully, the other provinces will follow the lead of Quebec and allow appropriate widespread access to Fibroscan.

Eric M Yoshida MD MHSc FRCPC, Victoria Y Kan BSc MHA, Jo-Ann E Ford MScN, Vladimir Marquez Azalgara MD MSc FRCPC

Division of Gastroenterology, University of British Columbia, Vancouver General Hospital, Vancouver, British Columbia 


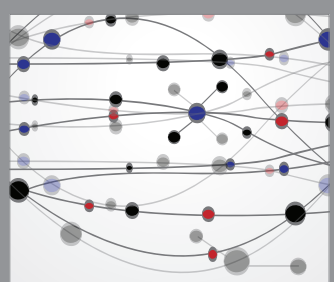

The Scientific World Journal
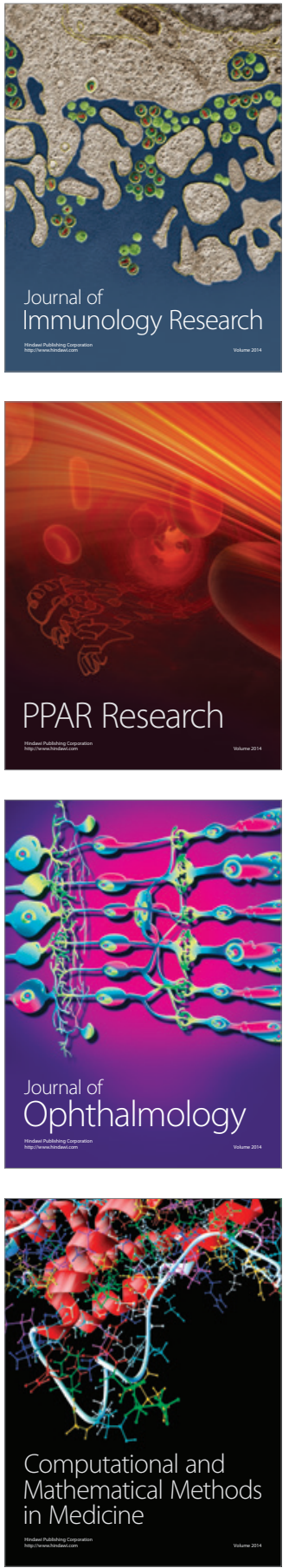

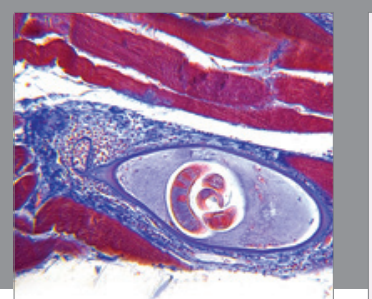

Gastroenterology Research and Practice

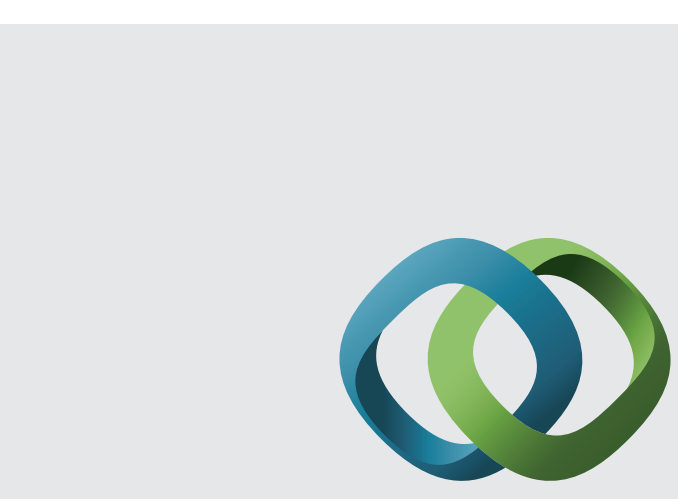

\section{Hindawi}

Submit your manuscripts at

http://www.hindawi.com
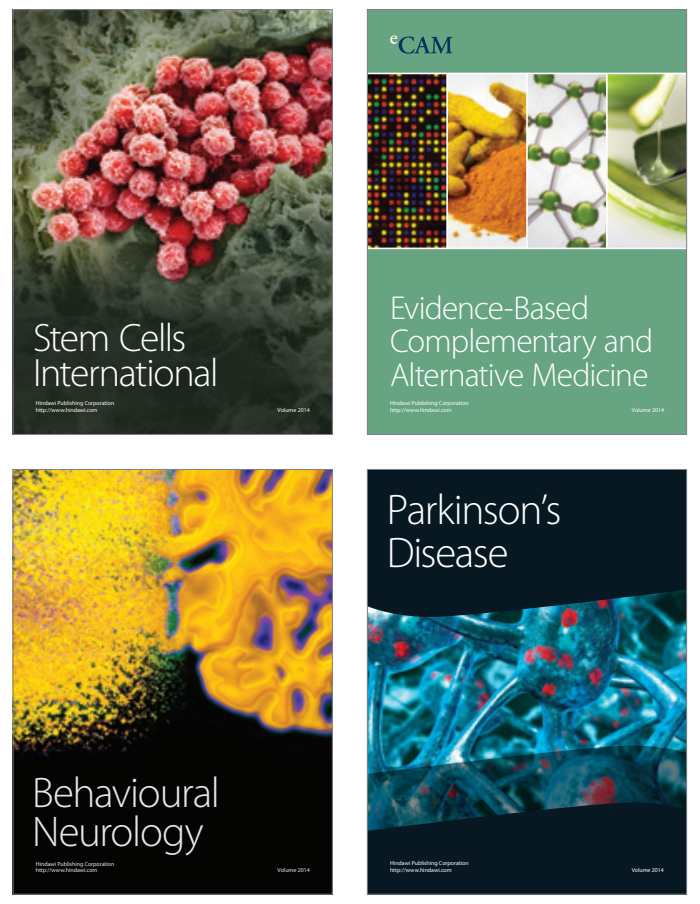
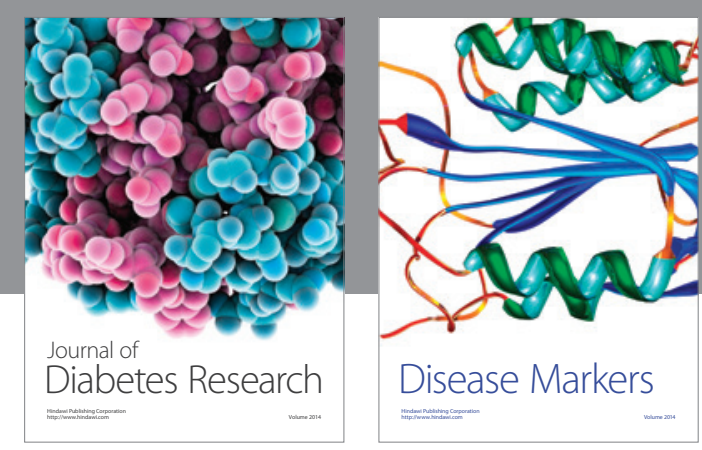

Disease Markers
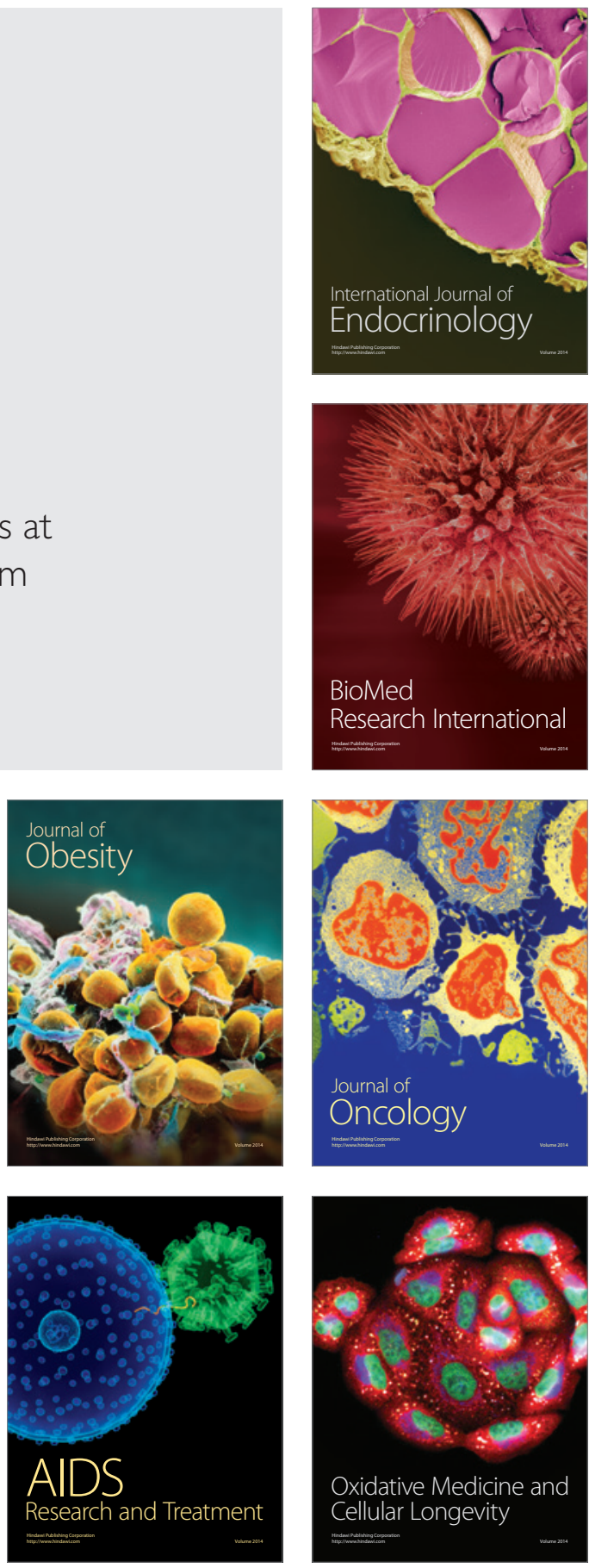